\title{
Análise de trilha para componentes do rendimento e caracteres agronômicos de trigo sob desfolha
}

\author{
Tânia Cristina de Oliveira Gondim(1), Valterley Soares Rocha(1), \\ Carlos Sigueyuki Sediyama ${ }^{(1)}$ e Glauco Vieira Miranda ${ }^{(1)}$
}

\footnotetext{
(1)Universidade Federal de Viçosa, Departamento de Fitotecnia, Avenida P.H. Holfs, s/no, CEP 36570-000 Viçosa, MG. E-mail: tgondim@yahoo.com, vsrocha@ufv.br, csediyama@ufv.br, glaucovmiranda@ufv.br
}

\begin{abstract}
Resumo - O objetivo deste trabalho foi avaliar a influência dos componentes do rendimento e caracteres da planta, na produção de grãos, em trigo sob desfolha, por meio da decomposição das correlações por meio de análise de trilha. O experimento foi conduzido em Viçosa, MG, em 2004. Os tratamentos constituíram-se de três níveis de desfolha e uma testemunha, com três variedades de trigo - Anahuac, BRS 207 e BR 24 -, com quatro repetições. A desfolha foi realizada com a retirada do limbo da folha bandeira, das segunda e terceira folhas superiores. Avaliaram-se: rendimento de grãos, peso do hectolitro, massa de mil grãos, número de espigas por parcela, número de grãos por espiga, biomassa seca do colmo, biomassa seca da palha da espiga, biomassa seca total, rendimento de grãos por espiga, biomassa seca do colmo individual, biomassa seca da palha da espiga individual e biomassa seca total por planta individual. A redução da biomassa seca do colmo levou a menores perdas de rendimento de grãos, pela remobilização de fotoassimilados com a desfolha. A massa de mil grãos e o número de grãos por espiga foram os principais componentes de rendimento. A seleção direta para esses caracteres é estratégia eficiente para aumentar o rendimento de grãos em trigo sob desfolha.
\end{abstract}

Termos para indexação: Triticum aestivum, correlação genética, estresse.

\section{Path analysis for yield components and agronomic traits of wheat under defoliation}

\begin{abstract}
The objective of this work was to evaluate the influence of yield components and plant characters in grain production, in wheat under defoliation, through correlations decomposition using path analysis. The experiment was accomplished in Viçosa, MG, Brazil, in 2004. The treatments consisted of three levels of defoliation and a control, with three wheat varieties - Anahuac, BRS 207 and BR 24 -, with four replicates. Defoliation was carried out by removing the blade of flag leaves from the second and third top leaves. The following parameters were evaluated: grain yield, hectolitric weight, one thousand-grain weight, number of spikes per plot, number of grain per spike, culm dry biomass, spike-straw dry biomass, total dry biomass, grain yield per spike, total dry biomass of individual culm, straw dry biomass of individual spike and total dry biomass per individual plant. The reduction in culm dry biomass led to lower losses of grain yield because of the higher remobilization of photoassimilates with defoliation. Thousand-grain weight and number of grain per spike were the main yield components. The direct selection for these characters is an efficient strategy to increase grain yield in wheat under defoliation.
\end{abstract}

Index terms: Triticum aestivum, genetic correlation, stress.

\section{Introdução}

Em programas de melhoramento de plantas cultivadas, cujo objetivo é a produção de grãos, são selecionados os genótipos com maior capacidade de rendimento. O rendimento de grãos, como produto final, resulta da interação de diversos fatores genéticos, fisiológicos e ambientais e, por isso, não pode ser considerado isoladamente. Portanto, estudos de componentes de rendimento de grãos são importantes no melhoramento genético do trigo (Souza, 1985).

Correlações entre o rendimento de grãos e seus componentes primários têm sido objeto de estudo de trabalhos sobre diversas culturas. $\mathrm{O}$ rendimento de grãos foi descrito como produto de vários componentes de rendimento (Nedel, 1994). Em cereais com população de plantas constante, o rendimento de grãos pode ser obtido principalmente pelo produto de três componentes 
principais: número de espigas por unidade de área, número de grãos por espiga e massa média do grão, e esses três componentes, até certo limite, variam independentemente um do outro.

Nos programas de melhoramento genético, utiliza-se a correlação entre caracteres, e sua importância reside no fato de se poder avaliar o quanto da alteração de um caráter pode afetar os demais, no decurso da seleção (Santos et al., 2000). Por meio do conhecimento da magnitude do desempenho de uma característica, pode-se avaliar a influência sobre outra característica. Entretanto, podem ocorrer alguns equívocos nas estratégias de seleção das características avaliadas, a partir da quantificação da magnitude das correlações entre as variáveis. Assim, apesar da utilidade dessas estimativas, no entendimento de um caráter de herança quantitativa como o rendimento de grãos, elas não determinam a importância relativa das influências diretas e indiretas desses caracteres que compõem o rendimento. A quantificação e a interpretação da magnitude do coeficiente de correlação, entre dois caracteres, podem levar a equívocos de seleção, pois a elevada correlação pode ser resultante do efeito de um terceiro ou de um grupo de caracteres (Cruz \& Carneiro, 2003).

Para entender melhor as associações entre diferentes caracteres, Wright (1921) propôs um método de desdobramento das correlações estimadas, em efeitos diretos e indiretos das variáveis sobre uma variável básica. Este método é denominado análise de trilha ou análise de caminhamento.

O sucesso da análise de trilha reside basicamente na formulação do relacionamento de causa e efeito entre as variáveis. Além disso, o desdobramento de correlações é dependente do conjunto de caracteres estudados, que normalmente é estabelecido pelo conhecimento prévio do pesquisador, de sua importância e de possíveis inter-relações expressas em diagramas de trilha (Cruz \& Regazzi, 1997).

$\mathrm{O}$ ambiente influencia a relação entre os componentes de rendimento. Denčić et al. (2000) avaliaram o rendimento de trigo e seus componentes, em condições ótimas de cultivo e sob estresse hídrico, e verificaram, pela análise de trilha, que para cultivares sob condições próximas do ótimo, não houve associação direta significativa das características analisadas com a produção, enquanto sob condições de estresse, o número de grãos por espiga teve efeito direto positivo e significativo.
Situações de estresse e danos foliares podem levar à alteração na redistribuição de fotoassimilados e alterar a relação fonte-dreno. O estudo dessa relação é importante para o conhecimento do funcionamento da partição de assimilados na planta.

O objetivo deste trabalho foi avaliar as associações entre componentes de rendimento, caracteres da planta e o rendimento de grãos, e determinar os efeitos diretos e indiretos desses componentes em genótipos de trigo sob desfolha, pela análise de trilha.

\section{Material e Métodos}

Foram utilizadas as variedades Anahuac, BRS $207 \mathrm{e}$ BR 24, obtidas junto ao banco de germoplasma do programa de melhoramento de trigo, da Universidade Federal de Viçosa (UFV). Antes da semeadura, foi realizado o teste de germinação para correção da população de plantas por parcela. O experimento foi instalado no Campo Experimental Professor Diogo Alves de Mello, do Departamento de Fitotecnia, na UFV, em 26 de maio de 2004.

O delineamento utilizado foi o de blocos ao acaso, em parcelas subdivididas. Os tratamentos constituíram-se de três variedades (na parcela), três níveis de desfolha e uma testemunha, sem desfolha, para cada variedade (na subparcela), com quatro repetições. Cada unidade experimental constituiu-se de quatro linhas de $1 \mathrm{~m}$ de comprimento e de $20 \mathrm{~cm}$ entre linhas, com densidade de 350 plantas por $\mathrm{m}^{2}$. O controle de plantas daninhas foi realizado com o uso do herbicida metsulfurom metyl, na dose $4 \mathrm{~g} \mathrm{ha}^{-1}$, e a aplicação do fungicida tebuconazole, na dose $750 \mathrm{~mL} \mathrm{ha}^{-1}$, para evitar danos por doenças. $\mathrm{O}$ ensaio foi conduzido sob irrigação.

A desfolha foi realizada na fase de espigamento, com a retirada do limbo da folha bandeira, das segunda e da terceira folhas superiores. A colheita foi realizada manualmente, com o corte das plantas rente ao solo, entre 23 e 25 de setembro de 2004.

Foram avaliados os seguintes caracteres: rendimento de grãos, obtido pela pesagem do total de grãos das parcelas, ajustado para $13 \%$ de umidade; peso do hectolitro, determinado nos grãos limpos e secados; massa de mil grãos; número de espigas por parcela, obtido pela contagem do número total de espigas por parcela; número de grãos por espiga, determinado de forma indireta, pela massa de mil grãos, número de espigas por parcela e rendimento de grãos por parcela; biomassa seca do colmo, obtida pela pesagem do total 
de plantas sem espigas, secadas em estufa por 48 horas a $75^{\circ} \mathrm{C}$; biomassa seca da palha de espiga, obtida com as espigas retiradas de todas as plantas, com a palha secada em estufa por 48 horas, a $72^{\circ} \mathrm{C}$; biomassa seca total, obtida pela soma da biomassa seca do colmo, biomassa seca da palha da espiga e da semente seca; rendimento de grãos por espiga, obtido de forma indireta pelo peso do total de grãos por parcela, ajustado para $13 \%$ de umidade, dividido pelo número de espigas da parcela; biomassa seca do colmo individual, obtida pela divisão do valor da biomassa seca do colmo pelo número de colmos por parcela; biomassa seca da palha da espiga individual, obtida pela divisão do valor da biomassa seca da palha da espiga pelo número de espigas por parcela; e biomassa seca total por planta individual, obtida pela divisão do peso da biomassa seca total pelo número de plantas.

As análises de correlação de Pearson e de trilha foram realizadas com o programa Genes (Cruz, 2001). Nas análises, foram consideradas as quatro repetições de cada nível de desfolha, em um total de 16 observações para cada variável analisada.

Inicialmente, foi feita a análise de trilha com os dados por parcela, em que o rendimento de grãos foi considerado como variável básica. O peso do hectolitro, massa de mil grãos, biomassa seca do colmo, biomassa seca da palha da espiga, biomassa seca total, número de espigas e número de grãos por espigas, foram considerados as variáveis primárias ou variáveis explicativas.

Foi realizada a avaliação de multicolinearidade, conforme Cruz \& Regazzi (1997). O grau de multicolinearidade da matriz de correlações, entre as variáveis independentes do modelo de regressão, foi estabelecido com base em seu número de condições, que é a razão entre o maior e o menor autovalor da matriz de correlação genética. Assim, quando o número de condições é menor que 100, a multicolinearidade é fraca e não ocasiona problema para a análise; quando se situa entre 100 e 1.000 , a multicolinearidade é de moderada a forte; e quando é maior que 1.000, a multicolinearidade é severa (Montgomery \& Peck, 1981).

Foi realizada, também, a análise de trilha com os dados por planta individual, em que o rendimento de grãos por espiga foi considerado a variável básica, e as variáveis massa de mil grãos, número de espigas, número de grãos por espiga, biomassa seca do colmo individual, biomassa seca da palha da espiga por planta e biomassa seca total por planta individual foram consideradas as variáveis primárias ou variáveis explicativas.

\section{Resultados e Discussão}

A análises de variância em relação aos caracteres revelaram que os efeitos de genótipos e nível de desfolha apresentaram variações significativas, em relação à maioria dos caracteres avaliados (Tabela 1). Os coeficientes de variação dos caracteres oscilaram entre $1,06 \%$ (peso do hectolitro) e $13,17 \%$ (rendimento de grãos), o que conferiu boa precisão aos experimentos que, segundo Lúcio et al. (1999), são classificados como baixo e médio, respectivamente, e considerados habituais para ensaios agrícolas de trigo.

Foram detectadas multicolinearidades severas para as variáveis biomassa seca total por parcela e biomassa seca total por planta individual, as quais foram eliminadas das análises. A maioria dos trabalhos sobre análises de trilha não tem considerado os efeitos adversos da multicolinearidade sobre os estimadores de quadrados mínimos, adotados para a resolução dos sistemas de equações. Assim, os resultados obtidos podem não ser confiáveis. Entre os efeitos de uma elevada multicolinearidade podem ser citadas as estimativas instáveis do coeficiente de regressão e uma superestimativa dos efeitos diretos das variáveis explicativas sobre a principal, que podem levar a resultados equivocados (Cruz \& Carneiro, 2003).

Verificou-se alta correlação positiva e significativa entre a variável peso do hectolitro e rendimento de grãos (Tabela 2). No entanto, o efeito direto do peso do hectolitro foi muito baixo, tendo sido expressivo o seu efeito indireto via massa de mil grãos, número de grãos por espiga e número de espigas. Portanto, os efeitos indiretos observados foram os responsáveis pela alta correlação entre peso do hectolitro e rendimento de grãos.

A variável massa de mil grãos apresentou correlação positiva e significativa com rendimento de grãos (Tabela 2). Resultado semelhante foi encontrado por Bhutta et al. (2005), que estudaram as relações de causa e efeito de componentes de rendimento. A quase totalidade do valor da correlação, observada no presente trabalho, deveu-se ao efeito direto dessa variável; essa é uma das mais importantes características, quando se deseja fazer seleção para o rendimento de grãos.

A massa de mil grãos também afetou o rendimento de forma positiva via número de grãos por espiga 


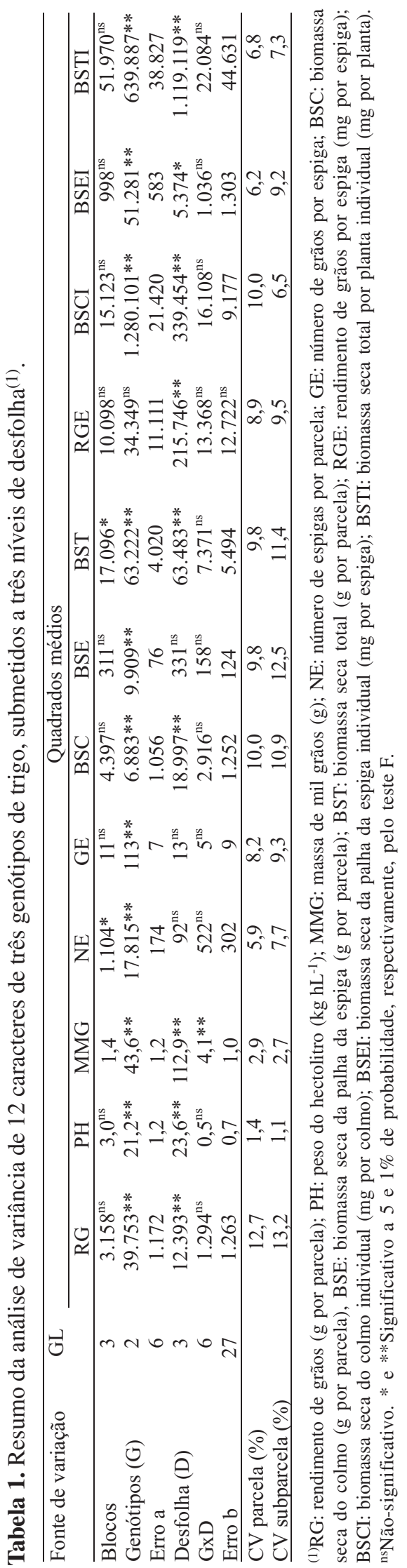

(Tabela 2). O rendimento de grãos foi afetado de forma negativa, mas em pequena magnitude, pela variável massa de mil grãos, via número de espigas, o que pode ter ocorrido em virtude da competição entre plantas por nutrientes, para suprir a demanda de assimilados em situação de estresse pela desfolha.

Observou-se que todas as variáveis apresentaram efeito indireto baixo e negativo sobre o rendimento de grãos, via biomassa seca do colmo (Tabela 2). Essa variável mostrou alta correlação, positiva e significativa, com rendimento de grãos, mas o seu efeito direto foi pequeno e negativo. Isto sugere que quando se realiza a desfolha, a diminuição da biomassa seca do colmo, em virtude da remobilização de assimilados do colmo, para atender à demanda durante a fase de enchimento de grãos, pode levar a menores perdas no rendimento de grãos. Essa capacidade de translocar reservas de outras partes da planta, que não das folhas, durante a fase em que a demanda é alta, é uma característica desejável do ponto de vista de produtividade que tem sido buscada no melhoramento do trigo.

Verificou-se alta correlação positiva e significativa entre biomassa seca da palha da espiga e rendimento de grãos (Tabela 2). No entanto, o efeito direto foi inexpressivo. Isso justifica, também, porque apenas o estudo de correlação não seria eficiente na seleção de características, durante o processo de melhoramento genético de plantas.

No presente trabalho, observou-se, no estudo de correlação, que a biomassa da parte aérea (biomassas secas do colmo e da palha da espiga) foi um dos principais caracteres da planta relacionado ao aumento do rendimento de grãos, entretanto, na análise de trilha, sua importância foi secundária. A esse respeito, Okuyama et al. (2004) afirmaram que o estudo mais detalhado das relações, obtidas pela análise de trilha, mostrou que a relação entre rendimento de grãos e seus componentes é bastante diferente das apresentadas pela análise de correlação simples. A aparente divergência ocorre em razão da abordagem analítica. Enquanto a correlação simples identifica as associações mútuas entre as características, a análise de trilha permite a determinação da magnitude relativa de cada efeito (Cruz \& Regazzi, 1997).

Constatou-se correlação positiva e significativa de número de espigas por parcela e rendimento de grãos (Tabela 2). A magnitude do valor de correlação deveu-se principalmente ao efeito direto dessa variável, o que 
mostra que ela é importante para o rendimento de grãos. Observou-se, também, efeito de número de espigas no rendimento, via efeito indireto de número de grãos por espiga. Segundo Blue et al. (1990), sob condições de estresse que resultam em baixo perfilhamento, o peso de grãos é extremamente importante na determinação do rendimento de grãos, enquanto sob condições ideais para o perfilhamento, o número de espigas é o mais importante componente de rendimento de grãos.

O alto valor positivo e significativo da correlação, entre número de grãos por espiga e rendimento de grãos, deveu-se principalmente ao seu efeito direto (Tabela 2). O número de grãos por espiga também afetou o rendimento de grãos de forma positiva, via efeito indireto da massa de mil grãos e via número de espigas, o que confirma serem essas variáveis as que mais influenciaram o rendimento em situação do estresse pela desfolha. Resultados semelhantes foram obtidos por Okuyama et al. (2004), que estudaram a relação dos componentes de rendimento de trigo irrigado e não irrigado. Vieira et al. (2007) avaliaram as correlações genéticas e seus desdobramentos, em efeitos diretos e indiretos de componentes primários e secundários sobre o rendimento de grãos, em 19 genótipos de trigo, e concluíram que um dos fatores primários, que apresentaram a maior importância na determinação do rendimento de grãos, foi o caractere número de grãos por espiga.

O número de grãos por metro quadrado está relacionado à capacidade da planta em acumular biomassa e transferi-la às estruturas reprodutivas em pré-antese (Rodrigues, 2002).

Os resultados da análise de trilha da avaliação por planta estão coerentes com os resultados da análise por parcela. As variáveis analisadas apresentaram altas correlações positivas e significativas com rendimento de grãos por planta. Apenas a variável número de espigas não apresentou correlação significativa com rendimento por planta; além disso, contribuiu com efeito indireto negativo para o rendimento, quando consideradas as outras variáveis (Tabela 3). Silva et al. (2005) avaliaram os componentes de rendimentos em trigo, e obtiveram resultados semelhantes. Esses autores observaram, ainda, quanto ao caráter número de espigas, com coeficiente de correlação positivo e efeito direto negativo sobre o rendimento de grãos, que a pressão de seleção intensificada sobre o número de espigas poderia não proporcionar ganhos genéticos satisfatórios no rendimento de grãos.
A massa de mil grãos foi a variável com maior efeito direto e indireto, nas análises dos componentes de rendimento, em situação de desfolha. O mesmo resultado

Tabela 2. Estimativas dos efeitos diretos e indiretos, e correlação entre a variável rendimento de grãos ( $R G$, g por parcela) e as variáveis: peso do hectolitro $\left(\mathrm{PH}, \mathrm{kg} \mathrm{hL}^{-1}\right)$, massa de mil grãos (MMG, g), biomassa seca do colmo (BSC, g por parcela), biomassa seca da palha da espiga (BSE, g por parcela), número de espigas por parcela $(\mathrm{NE})$ e número de grãos por espiga (GE), em três genótipos de trigo (Anahuac, BRS 207 e BR 24) submetidos a três níveis de desfolha.

\begin{tabular}{|c|c|c|c|}
\hline Efeito & Efeito direto & Efeito indireto & r de Pearson \\
\hline & \multicolumn{3}{|c|}{ Peso do hectolitro } \\
\hline Direto sobre RG & 0,051 & - & - \\
\hline Indireto via $\mathrm{MMG}$ & - & 0,465 & - \\
\hline Indireto via BSC & - & $-0,019$ & - \\
\hline Indireto via BSE & - & 0,030 & - \\
\hline Indireto via NE & - & 0,116 & - \\
\hline Indireto via GE & - & 0,261 & - \\
\hline \multirow[t]{2}{*}{ Total (r de Pearson) } & - & - & $0,904 * *$ \\
\hline & \multicolumn{3}{|c|}{ Massa de mil grãos } \\
\hline Direto sobre RG & 0,539 & - & - \\
\hline Indireto via $\mathrm{PH}$ & - & 0,044 & - \\
\hline Indireto via $\mathrm{BSC}$ & - & $-0,015$ & - \\
\hline Indireto via BSE & - & 0,018 & - \\
\hline Indireto via NE & - & $-0,022$ & - \\
\hline Indireto via GE & - & 0,153 & - \\
\hline \multirow[t]{2}{*}{ Total (r de Pearson) } & - & - & $0,716^{* *}$ \\
\hline & \multicolumn{3}{|c|}{ Biomassa seca do colmo por parcela } \\
\hline Direto sobre RG & $-0,021$ & - & - \\
\hline Indireto via $\mathrm{PH}$ & - & 0,047 & - \\
\hline Indireto via $\mathrm{MMG}$ & - & 0,401 & - \\
\hline Indireto via BSE & - & 0,035 & - \\
\hline Indireto via NE & - & 0,199 & - \\
\hline Indireto via GE & - & 0,309 & - \\
\hline \multirow[t]{2}{*}{ Total (r de Pearson) } & - & - & $0,971 * *$ \\
\hline & \multicolumn{3}{|c|}{ Biomassa seca da palha da espiga por parcela } \\
\hline Direto sobre RG & 0,042 & - & - \\
\hline Indireto via $\mathrm{PH}$ & - & 0,036 & - \\
\hline Indireto via $\mathrm{MMG}$ & - & 0,235 & - \\
\hline Indireto via BSC & - & $-0,017$ & - \\
\hline Indireto via NE & - & 0,242 & - \\
\hline Indireto via GE & - & 0,343 & - \\
\hline \multirow[t]{2}{*}{ Total (r de Pearson) } & - & - & $0,883 * *$ \\
\hline & \multicolumn{3}{|c|}{ Número de espigas por parcela } \\
\hline Direto sobre RG & 0,361 & - & - \\
\hline Indireto via $\mathrm{PH}$ & - & 0,016 & - \\
\hline Indireto via $\mathrm{MMG}$ & - & $-0,033$ & - \\
\hline Indireto via $\mathrm{BSC}$ & - & $-0,011$ & - \\
\hline Indireto via BSE & - & 0,028 & - \\
\hline Indireto via GE & - & 0,216 & - \\
\hline \multirow[t]{2}{*}{ Total (r de Pearson) } & - & - & $0,578 *$ \\
\hline & \multicolumn{3}{|c|}{ Número de grãos por espiga } \\
\hline Direto sobre RG & 0,398 & - & - \\
\hline Indireto via $\mathrm{PH}$ & - & 0,033 & - \\
\hline Indireto via $\mathrm{MMG}$ & - & 0,207 & - \\
\hline Indireto via BSC & - & $-0,016$ & - \\
\hline Indireto via BSE & - & 0,036 & - \\
\hline Indireto via NE & - & 0,196 & - \\
\hline Total (r de Pearson) & - & - & $0,855 * *$ \\
\hline Efeito da var. residual & 0,084 & 0,022 & 0,048 \\
\hline
\end{tabular}


Tabela 3. Estimativas dos efeitos diretos e indiretos, e correlação entre a variável rendimento de grãos por espiga (RGE, mg por espiga) e as variáveis: massa de mil grãos (MMG, $\mathrm{g})$, número de espigas por parcela $(\mathrm{NE})$, número de grãos por espiga (GE), biomassa seca do colmo individual (BSCI, mg por colmo) e biomassa seca da palha da espiga individual (BSEI, mg por espiga), em três variedades de trigo (Anahuac, BRS 207 e BR 24) submetidos a três níveis de desfolha.

\begin{tabular}{|c|c|c|c|}
\hline Efeito & Efeito direto & Efeito indireto & r de Pearson \\
\hline & \multicolumn{3}{|c|}{ Massa de mil grãos } \\
\hline Direto sobre RGE & 0,656 & - & - \\
\hline Indireto via NE & - & 0,001 & - \\
\hline Indireto via GE & - & 0,193 & - \\
\hline Indireto via BSCI & - & 0,029 & - \\
\hline Indireto via BSEI & - & 0,004 & - \\
\hline \multirow[t]{2}{*}{ Total (r de Pearson) } & - & - & $0,883 * *$ \\
\hline & \multicolumn{3}{|c|}{ Número de espigas por parcela } \\
\hline Direto sobre RGE & $-0,018$ & - & - \\
\hline Indireto via $\mathrm{MMG}$ & - & $-0,040$ & - \\
\hline Indireto via GE & - & 0,273 & - \\
\hline Indireto via BSCI & - & 0,005 & - \\
\hline Indireto via BSEI & - & 0,001 & - \\
\hline \multirow[t]{2}{*}{ Total (r de Pearson) } & - & - & 0,220 \\
\hline & \multicolumn{3}{|c|}{ Número de grãos por espiga } \\
\hline Direto sobre RGE & 0,502 & - & - \\
\hline Indireto via $\mathrm{MMG}$ & - & 0,252 & - \\
\hline Indireto via NE & - & $-0,010$ & - \\
\hline Indireto via BSCI & - & 0,021 & - \\
\hline Indireto via BSEI & - & 0,005 & - \\
\hline \multirow[t]{2}{*}{ Total (r de Pearson) } & - & - & $0,771 * *$ \\
\hline & \multicolumn{3}{|c|}{ Biomassa seca do colmo individual } \\
\hline Direto sobre RGE & 0,032 & - & - \\
\hline Indireto via $\mathrm{MMG}$ & - & 0,596 & - \\
\hline Indireto via $\mathrm{NE}$ & - & $-0,003$ & - \\
\hline Indireto via $\mathrm{GE}$ & - & 0,337 & - \\
\hline Indireto via BSEI & - & 0,005 & - \\
\hline \multirow[t]{2}{*}{ Total (r de Pearson) } & - & - & $0,968 * *$ \\
\hline & \multicolumn{3}{|c|}{ Biomassa seca da palha da espiga individual } \\
\hline Direto sobre RGE & 0,007 & - & - \\
\hline Indireto via $\mathrm{MMG}$ & - & 0,446 & - \\
\hline Indireto via NE & - & $-0,002$ & - \\
\hline Indireto via GE & - & 0,372 & - \\
\hline Indireto via BSCI & - & 0,026 & - \\
\hline Total (r de Pearson) & - & - & $0,848 * *$ \\
\hline Efeito da var. residual & 0,054 & 0,056 & 0,030 \\
\hline
\end{tabular}

**Significativo a $1 \%$ de probabilidade pelo teste $\mathrm{F}$.

foi obtido por Souza (1985), ao estudar correlações e coeficiente de trilha em trigo, em diferentes ambientes de Minas Gerais.

A biomassa seca, tanto do colmo como da palha da espiga, mostrou alta correlação com o rendimento de grãos por planta, porém os efeitos diretos foram muito baixos (Tabela 3). Os altos valores ocorreram em conseqüência dos efeitos indiretos via massa de mil grãos e via número de grãos por espiga. A forte associação entre número de grãos por unidade de área e rendimento de grãos indicaria que o fornecimento de assimilados para o enchimento dos grãos (capacidade da fonte), em conjunto com as reservas acumuladas em órgãos vegetativos, na fase de pré-antese, foram suficientes para satisfazer à demanda dos grãos em crescimento (capacidade dos destinos) (Rodrigues, 2002).

\section{Conclusões}

1. A massa de mil grãos e o número de grãos por espiga são os principais componentes de rendimento de grãos, para as variedades estudadas, sob desfolha.

2. O rendimento de grãos em plantas sob estresse de desfolha está associado à redução da biomassa seca do colmo.

3. A seleção direta para massa de mil grãos e número de grãos por espiga é estratégia eficiente para aumentar o rendimento de grãos em situação de estresse por perda de área foliar.

\section{Agradecimentos}

Ao Conselho Nacional de Desenvolvimento Científico e Tecnológico, pela concessão de bolsa e auxílios.

\section{Referências}

BHUTTA, W.M.; AKHTAR, J.; ANWAR-UL-HAQ, I.M. Cause and effect relations of yield components in spring wheat (Triticum aestivum L.) under normal conditions. Caderno de Pesquisa: Série Biologia, v.17, p.7-12, 2005.

BLUE, E.N.; MASON, S.C.; SANDER, D.H. Influence of planting date, seeding rate, and phosphorus rate on wheat yield. Agronomy Journal, v.82, p.762-768, 1990.

CRUZ, C.D. Programa GENES: aplicativo computacional em genética e estatística versão Windows. Viçosa: UFV, 2001. 442p.

CRUZ, C.D.; CARNEIRO, P.C.S. Modelos biométricos aplicados ao melhoramento de plantas. 3.ed. Viçosa: UFV, 2003. 585p.

CRUZ, C.D.; REGAZZI, A.J. Modelos biométricos aplicados ao melhoramento genético. 2.ed. Viçosa: UFV, 1997. 390p.

DENČIĆ, S.; KASTORI, R.; KOBILJSKI, B.; DUGGAN, B. Evaluation of grain yield and its components in wheat cultivars and landraces under near optimal and drought conditions. Euphytica, v.113, p.43-52, 2000.

LÚCIO, A.D.; STORCK, L.; BANZATTO, D.A. Classificação dos experimentos de competição de cultivares quanto a sua precisão. Pesquisa Agropecuária Gaúcha, v.5, p.99-103, 1999.

MONTGOMERY, D.C.; PECK, E.A.; VINING, G.G. Introduction to linear regression analysis. New York: John Wiley \& Sons, 1981. 504p.

NEDEL, J.L. Progresso genético no rendimento de grãos de cultivares de trigo lançadas para cultivo entre 1940 e 1992. Pesquisa Agropecuária Brasileira, v.29, p.1565-1570, 1994. 
OKUYAMA, L.A.; FEDERIZZI, L.C.; BARBOSA NETO, J.F. Correlation and path analysis of yield and its components and plant traits in wheat. Ciência Rural, v.34, p.1701-1708, 2004.

RODRIGUES, O.; DIDONET, A.D.; LHAMBY, J.C.B.; TEIXEIRA, M.C.C.; DEL DUCA, L. de J. Características fisiológicas associadas ao avanço no potencial de rendimento de grãos de trigo. Passo Fundo: Embrapa Trigo, 2002. 26p. (Embrapa Trigo. Boletim de Pesquisa e Desenvolvimento Online, 6).

SANTOS, R.C.; CARVALHO, L.P.; SANTOS, V.F. Análise de coeficiente de trilha para os componentes de produção em amendoim. Ciência e Agrotecnologia, v.24, p.13-16, 2000.

SILVA, S.A.; CARVALHO, F.I.F.; NEDEL, J.L.; CRUZ, P.J.; SILVA, J.A.G.; CAETANO, V.R.; HARTWIG, I.; SOUSA, C.S. Análise de trilha para os componentes de rendimento de grãos em trigo. Bragantia, v.64, p.191-196, 2005.

SOUZA, M.A. Adaptabilidade, estabilidade, correlações e coeficiente de trilha em genótipos de trigo (T. aestivum $\mathrm{L}$.), em doze ambientes de Minas Gerais. 1985. 118p. Dissertação (Mestrado) - Universidade Federal de Viçosa, Viçosa.

VIEIRA, E.A.; CARVALHO, F.I.F.; OLIVEIRA, A.C.; MARTINS, L.F.; BENIN, G.; SILVA, J.A.G.; COIMBRA, J.; MARTINS, A.F.; CARVALHO, M.F.; RIBEIRO, G. Análise de trilha entre os componentes primários e secundários do rendimento de grãos em trigo. Revista Brasileira de Agrociência, v.13, p.169-174, 2007.

WRIGHT, S. Correlation and causation. Journal of Agricultural Research, v.20, p.557-585, 1921.

Recebido em 17 de agosto de 2007 e aprovado em 28 de março de 2008 